\title{
Effectiveness of Myo-inositol and Combined Oral Contraceptives in Adolescent and Young Women with PCOS
}

\author{
Sujata Deo ${ }^{1}$, Khushbu Pandey ${ }^{1}$, Pratibha Kumari $^{3{ }^{*}}$, Narendra Deo $^{4}$, S.P. Jaiswar ${ }^{5}$, Md Kaleem Ahmad ${ }^{6}$, Monica \\ Agarwal $^{7}$ \\ ${ }^{1}$ Professor, Department of Obs and Gynae, King George's Medical University, Lucknow, India \\ ${ }^{2}$ Senior Resident, Department of Obs and Gynae, King George's Medical University, Lucknow, India \\ ${ }^{3}$ Department of Obs and Gynae, King George's Medical University, Lucknow, India \\ ${ }^{4}$ Senior Consultant, Balrampur Hospital, Lucknow, India \\ ${ }^{5}$ Professor and Unit Head, Department of Obs and Gynae, King George's Medical University, Lucknow, India \\ ${ }^{6}$ Associate Professor, Department of Biochemistry, King George's Medical University, Lucknow, India \\ ${ }^{7}$ Assistant Professor, Department of Obs and Gynae, King George's Medical University, Lucknow, India
}

*Address for Correspondence: Dr. Pratibha Kumari, Department of Obs and Gynae, King George's Medical University, Lucknow, U.P., India

E-mail: kgmu.prati2011@gmail.com

Received: 26 Sep 2020/ Revised: 23 Nov 2020/ Accepted: 03 Feb 2021

\begin{abstract}
Background: Polycystic ovary syndrome (PCOS) is a complex neuro-endocrine disorder and the most common endocrinopathy in reproductive-aged women with key features of menstrual irregularity, elevated androgens, and polycystic ovaries on ultrasound. Combined oral contraceptive pills have been used for the treatment of menstrual disorders, acne, and hirsutism. Another longterm treatment options include insulin-sensitizing drugs.

Methods: This prospective randomized study was conducted in the Department of Obstetrics and Gynaecology, in collaboration with the Department of Biochemistry, King George's Medical University, Lucknow. Adolescent and young women in the age group 14 to 24 years, attending the Gynae OPD having PCOS as defined by Rotterdam Criteria were registered and screened for inclusions in the study. Patients were randomly allocated to the treatment groups along with the lifestyle modification in each. Group I received low dose COCs, Group II received Myo-inositol and Group III received a combination of both COCs and Myoinositol. Post-treatment evaluation was done after 3 months of treatment.

Result: Treatment with Myo-inositol decreased body mass index, LH levels, improved insulin resistance as measured by fasting insulin, fasting glucose and homeostatic model assessment (HOMA-IR). COCs resulted in improved menstrual abnormality, improvement in the hormonal profile as increase in SHBG and reduction in LH, Free testosterone, FAI. Improvement in clinical features in terms of regularization of the menstrual cycle as well as serum Androgens, both groups saw a decrease in levels, but the combined therapy group saw a significant increase.

Conclusion: Combination of treatment with COCs and Myo-inositol can prove to be a more successful long-term treatment option for PCOS symptoms.
\end{abstract}

Key-words: Adolescent, Polycystic ovary syndrome, Myoinositol, Combined oral contraceptive, metabolic syndrome

\section{INTRODUCTION}

Polycystic ovary syndrome (PCOS) in women of reproductive age is known to be the most common endocrine metabolic disorder, with an onset that manifests as early as puberty.

\begin{tabular}{l} 
How to cite this article \\
Deo S, Pandey K, Kumari P, Deo N. Effectiveness of Myo-Inositol \\
and Combined Oral Contraceptives in Adolescent and Young \\
Women with PCOS. SSR Inst. Int. J. Life Sci., 2021; 7(2): 2763-2773. \\
\hline
\end{tabular}

Approximately $6-10 \%$ of women of childbearing age are affected by PCOS ${ }^{[1]}$. The majority of Adolescent and adult women accounting for irregular menstrual cycles, anovulatory infertility, hirsutism ${ }^{[2]}$, several variables are involved in PCOS pathogenesis. The signs and symptoms are heterogeneous and PCOS diagnosis can also be difficult ${ }^{[3]}$. Rotterdam criteria indicated PCOS to be present if two of three criteria are found: oligo-ovulation or anovulation (usually manifested as oligomenorrhea or amenorrhea), excess androgen activity (hirsutism, acne, seborrhea) and polycyctic ovaries at ultrasound ${ }^{[3]}$. The 
presence of polycystic ovaries is not the only diagnostic finding for PCOS, but their presence alone does not determine the diagnosis ${ }^{[3,4]}$. The functions of insulin resistance (IR) is central role in nearly $70-80 \%$ of obese females and $15-30 \%$ of lean females with PCOS ${ }^{[5]}$ and represent the pathogenic link in PCOS between reproductive and metabolic disorders ${ }^{[6]}$.

The use of inositol for the treatment of PCOS has seen in the previous decade, and a recent study indicates that inositol therapy can minimize insulin resistance, increase ovarian function and decrease androgen levels in women with PCOS ${ }^{[7]}$. Management of PCOS in adolescents and young with PCOS is based on presenting symptoms (menstrual irregularity and androgen excess) and it includes Lifestyle modification. The preferred effective method of treatment for obese adolescents with PCOS is lifestyle modification ${ }^{[8]}$; however, it is hard for patients to comply with and achieve this. A healthy lifestyle, including reduced carbohydrate intake and gentle exercise, is recommended to all patients as a first line non-pharmacological management weight loss increases SHBG, reduces free Testosterone, reduces insulin resistance and restores ovulation ${ }^{[3]}$. Weight loses and BMI decreasing to be quite pivotal after receiving and significant weight loss found in patients treated with Myo-inositol ${ }^{[9]}$.

Protected and viable treatment of youngsters influenced by PCOS is fundamental for enhancing clinical appearances, re-establishing, confidence and forestalling further intricacies, viability if $\mathrm{MI}$ and OCPs in the treatment of young females with PCOS by assessment of hormonal and metabolic profile There are limited studies amid uses of $\mathrm{MI}$ in adolescent ${ }^{[10]}$. The aim of the present study was to evaluate the effectiveness of Myo-inositol and COCs as single therapy ( $\mathrm{MI}$ or COCs) and in combination therapy ( $\mathrm{Ml}+\mathrm{COCS}$ ) in adolescent and young women of age group (14-24 years) with PCOS, along with life style modification.

\section{MATERIALS AND METHODS}

This Prospective Randomized Open labeled study was conducted in the Department of Obstetrics and Gynaecology, in collaboration with the Department of Biochemistry, King George's Medical University, Lucknow, India after ethical clearance for the duration of one year in 2018 (2018-2019). In this study 64 adolescent girls and young women aged 14-24 years affected by PCOS as defined by Rotterdam Criteria ${ }^{[3]}$, who attending the Gynaecology OPD from the Department of Obstetrics and Gynaecology. All the participants were registered and screened after taken informed written consent before entering this study.

Inclusion Criteria- The participants, who was menstrual irregularity (oligomenorrhoea/ amenorrhoea), signs of hyperandrogenism (hirsutism, acne, central alopecia) and signs of hyperinsulinemia- (obesity, acanthosis nigricans), polycystic ovaries on ultrasound included in this study.

Exclusion Criteria- The participant, who was pregnancy, hypothyroidism, hyperprolectimea, adrenal hyper androgenaemia, cushing's syndrome and patients within two years of menarche excluded in this study.

Subject Recruitment- Menstrual history in detail was taken including age, age at menarche, menstrual history regarding oligomenorrhea/ amenorrhea/ hypo menorrhea/ menorrhagia. A detailed history was obtained from cases for the intake of any hormonal drugs, including COCs as well as medication for lowering Serum glucose. Detailed Physical examination was done including- Blood pressure, Secondary sexual characters (tanner staging), weight, height, BMI, waist hip ratio, Androgen status assessment-hirsutism (modified ferriman-gallwey scoring), acne, insulin resistance features (acanthosis nigricans), Moon facies/ striae (if any). Clinical hyperandrogenism was defined using a modified Ferriman-Gallwey (FG) score for evaluating and quantifying hirsutism in women using nine body areas (upper lip, chin, chest, upper and lower abdomen, thighs, upper and lower back and upper arm). Hair growth was rated from 0 (no growth of terminal hair) to 4 (extensive hair growth) in each of the nine locations. Score indicative of androgen excess as $<4$ considered as mild, 4 to $\leq 8$ as moderate and $\geq 8$ as severe hirsutism.

$\mathrm{BMI}$ was calculated as $\mathrm{BMI}=$ Weight $/$ height $^{2}$, in kilogram per meter ${ }^{2}$. Cut-off body mass index (BMI) with body fat as Standard Consensus Statement for Indian population was considered, i.e. Underweight: BMK $18.5 \mathrm{~kg} / \mathrm{m}^{2}$, Normal BMI: $18.0-22.9 \mathrm{~kg} / \mathrm{m}^{2}$, Overweight: $23.0-24.9$ $\mathrm{kg} / \mathrm{m}^{2}$, and $\mathrm{BMI} \geq 25$ was considered as obese.

Waist-to-hip ratio (WHR ratio) was calculated as a marker of body fat distribution at baseline, according to the standard formula: 
WHR= waist circumference $(\mathrm{cm}) /$ hip circumference (cm)

Determination of polycystic ovaries was confirmed by ultrasound, in 1 or both ovaries, either 12 or more follicles measuring 2-9 $\mathrm{mm}$ in diameter $O R$ increased ovarian volume $>10 \mathrm{~cm}^{3}$, Identification of endometrial abnormality.

Sample collection- Blood sample were collected the time of enrollment for the baseline information on Day 2/ Day 3 of menses and after three month treatment. All the participants were asked to respect an overnight fast before blood collection. Other specific investigations as per requirement were assessed.

Hormonal assessment- Serum Total and Free testosterone, SHBG (sex hormone binding globulin), thyroid profile (serum T3, T4, TSH), Serum prolactin, Serum FSH (Follicle stimulating hormone) and Serum LH (luteinizing hormone), Fasting insulin, Fasting glucose, 17 $\mathrm{OH}$ progesterone (to rule out Non classical CAH) (if indicated) assessed at 8am, USG scan (trans-abdominal). The free androgen index was calculated as follows: FAI= Total Testosterone $(\mathrm{nmol} / \mathrm{l})$ to SHBG $(\mathrm{nmol} / \mathrm{l})$ ratio $\times 100$. Insulin resistance was assessed via calculation of the homeostasis model assessment insulin resistance index (HOMA-IR=fasting glucose in $\mu \mathrm{IU} / \mathrm{ml} \times$ fasting insulin in $\mathrm{mg} / \mathrm{dl} / \mathrm{405}$ ).

Computer Generated randomization was done to assign patients into three groups. In the patients with secondary amenorrhea withdrawal bleeding with (10 $\mathrm{mg}$ ) Medroxyprogesterone acetate was induced before the commencement of treatment.

All the patients were recommended for lifestyle modification in the form of reduced calorie diet and gentle exercise (150 minutes per week of brisk exercise) as first line non-pharmacological management.

Group I- 21 patients, who received low dose combined OCP (Drospirenone $3 \mathrm{mg}+$ Ethinyl Estradiol 30 $\mu \mathrm{g}$ ) consumed cyclically starting either from day 3 to day 5 of menstruation $\times 21$ days for 3 months.

Group II- 21 patients, who received (2 g Myo-inositol + $200 \mathrm{mg}$ folic acid) twice daily for 3 months.

Group III- 22 patients, who received Low dose combined OCP (Drospirenone $3 \mathrm{mg}$ + Ethinyl Estradiol $30 \mu \mathrm{g}$ ) consumed cyclically starting from either day 3 to day 5 of menstruation $\times 21$ days for 3 months + ( 2 g Myo-inositol $+200 \mathrm{mg}$ folic acid) twice daily for 3 months.

Reviewed Evaluation of the patients in terms of Anthropometric, clinical, endocrine and metabolic parameters was done after 3 months of treatment. Outcome variables are-

- Clinical response in terms of improvement in clinical symptoms and side effects

- Anthropometric : Change in weight, BMI, waist hip ratio

- Change in hormonal parameters

Statistical Analysis- The statistical analysis was done using SPSS (Statistical Package for Social Sciences) Version 21.0 statistical Analysis Software. The values were represented in Number (\%) and Mean \pm SD. Analysis of Variance ANOVA test was used to compare the within group and between group variances amongst the study groups. Analysis of variance of different study groups at a particular time interval revealed the differences amongst them. ANOVA provided "F" ratio, where a higher "F" value depicted a higher inter-group difference. To compare the change in a parameter at two different time intervals paired "t" test was used. Significance level was set at $p<0.05, p<0.01$ and $p<0.001$.

Ethical approval- Ethical clearance was approved by Institutional Ethics committee of Research cell, King George's Medical University, Lucknow (Ref. code: $88^{\text {th }}$ RCM 11 B- Thesis/P27).

\section{RESULTS}

In all three study groups, Table 1 shows that majority of 39 (60.9\%) cases were aged 20-24 years and 25 (39.1\%) cases aged 14-19 years. The mean age of cases was $20.16 \pm 2.16$ years. The majority of cases attained menarche at the age $\geq 12$ to 14 years $(71.9 \%)$ followed by those reporting it to be $<12$ years $(23.4 \%)$ and $>14$ years $(4.7 \%)$, respectively. Maximum cases were in normal BMI category $(43.8 \%)$ followed by those in the overweight (28.1\%), obese $(25.0 \%)$ and underweight $(5.1 \%)$ category (Table 1). A total of $20(31.3 \%)$ cases had waist circumference $>80 \mathrm{~cm}$. The majority of the cases had waist-hip ratio $\geq 0.85$ (54.7\%). There were 29 (45.3\%) cases with WHR $<0.85$. 
Table 1: Distribution of cases Anthropometric characteristics $(n=64)$

\begin{tabular}{lcc}
\hline Parameters & Number & $\begin{array}{c}\text { Percentage } \\
\text { (\%) }\end{array}$ \\
\hline BMI (kg/m $)^{[11]}$ & 2 & 5.1 \\
Underweight $(<18.5)$ & 28 & 43.8 \\
Normal (18.5-22.9) & 18 & 28.1 \\
Overweight (23-24.9) & 16 & 25.0 \\
Obese ( $\geq 25)$ & 20 & 31.3 \\
Waist Circumference and Waist Hip Ratio ${ }^{[11]}$ & \\
Waist circumference & & \\
(>80 cm) & 44 & 68.7 \\
Waist circumference & & \\
(<80 cm) & & \\
Waist hip ratio (WHR) & & \\
$\quad<0.85$ & 29 & 45.3 \\
$\quad \geq 0.85$ & 35 & 54.7 \\
\hline
\end{tabular}

Signs of hirsutism were seen in 19 (29.7\%) cases-among these 1 (1.6\%) had mFGS in the range of 1-4 (mild hirsutism), 6 (9.3\%) had mFGS in 4-8 range (moderate hirsutism) and 12 (18.8\%) had mFGS >8 (severe hirsutism). A total of 13 (20.3\%) cases had acne. Signs and symptoms of insulin resistance/ hyperinsulinemia were measured in terms of acanthosis nigricans and obesity in $9.4 \%$ and $25 \%$ of patients, respectively (Table 2).

Table 2: Distribution of cases according to signs and symptoms of Androgen excess (Hirsutism, Acne) and Insulin Resistance (Acanthosis nigricans and Obesity) $(n=64)$

\begin{tabular}{lcc}
\hline Signs and symptoms & Number & Percentage (\%) \\
\hline Hirsutism & 19 & 29.7 \\
*mFGS(1- 4) & 1 & 1.6 \\
mFGS (4- 8) & 6 & 9.3 \\
mFGS( >8) & 12 & 18.8 \\
Acne & 13 & 20.3 \\
Acanthosis nigricans & 6 & 9.4 \\
Non Obese & 48 & 75.0 \\
Obese & 16 & 25.0 \\
\hline
\end{tabular}

Table 3 shows the distribution of cases according to menstrual irregularity, except for $1(1.6 \%)$ case, who that presented with a normal menstrual cycle, all the others had an abnormal menstrual cycle. Among menstrual abnormalities, oligomenorrhea was the most common in $32(50 \%)$ followed by secondary amenorrhea in 14 (21.8\%), oligomenorrhea with hypomenorrhea in 9 (14.1\%) and oligomenorrhea with menorrhagia in 8 (12.5\%) cases, respectively.

Table 3: Distribution of cases according to the menstrual irregularity $(n=64)$

\begin{tabular}{|c|c|c|c|}
\hline S.No. & Symptom & Number & $\begin{array}{c}\text { Percentage } \\
\text { (\%) }\end{array}$ \\
\hline 1. & $\begin{array}{l}\text { Normal menstrual } \\
\text { cycle }\end{array}$ & 1 & 1.6 \\
\hline 2 & $\begin{array}{l}\text { Abnormal } \\
\text { menstrual cycle }\end{array}$ & 63 & 98.4 \\
\hline a. & Oligomenorrhea & 32 & 50.0 \\
\hline b. & $\begin{array}{l}\text { Secondary } \\
\text { Amenorrhea }\end{array}$ & 14 & 21.8 \\
\hline c. & $\begin{array}{l}\text { Oligomenorrhea+ } \\
\text { hypomenorrhea }\end{array}$ & 9 & 14.1 \\
\hline d. & $\begin{array}{l}\text { Oligomenorrhea+ } \\
\text { menorrhagia }\end{array}$ & 8 & 12.5 \\
\hline
\end{tabular}

The cases in the three groups had matched age and anthropometric profile at the time of enrolment. The age of cases ranged from 16 to 24 years. The mean age of patients in Groups I, II and III were 20.52 \pm 2.25 , $20.19 \pm 1.99$ and $19.77 \pm 2.20$ years, respectively. On evaluating the data statistically, the difference in mean age of patients was not significant $(p=0.521)$. BMI $(p=0.103)$ waist circumference $(p=0.091)$, hip circumference $p=0.901$ and WHR $(p=0.112)$ of patients were respectively in Groups I, II and III. On evaluating the data statistically, the difference among groups was not significant.

Correlation of the Baseline clinical features of PCOS among the three groups, in Table 5 chi squire test $\left(\chi^{2}\right)$ Shows that there was no significant difference found in Menstrual abnormalities, Acne hirsutism, and Acanthosis nigricans among all groups according to type of menstrual complaints $(p=0.792)$. 
Table 4: Correlation of the Baseline Anthropometric characteristics of the cases among the three groups

\begin{tabular}{|c|c|c|c|c|c|}
\hline SN & Characteristic & $\begin{array}{c}\text { Group I }(\mathrm{n}=21) \\
\text { COCs (Drospirenone + } \\
\text { Ethinyl Estradiol ) } \\
\text { (Mean } \pm \text { SD) }\end{array}$ & $\begin{array}{l}\text { Group II ( } n=21) \\
\text { Myo-inositol } \\
\text { (Mean } \pm S D)\end{array}$ & $\begin{array}{c}\text { Group III ( } n=22) \\
\text { Myo-inositol + } \\
\text { COCs } \\
\text { (Mean } \pm \text { SD) } \\
\end{array}$ & $\begin{array}{l}\text { Statistical } \\
\text { significance }\end{array}$ \\
\hline 1. & $\begin{array}{l}\text { Mean Age } \pm \text { SD } \\
\text { (Range) in years }\end{array}$ & $\begin{array}{c}20.52 \pm 2.25 \\
(17-25)\end{array}$ & $\begin{array}{c}20.19 \pm 1.99 \\
(17-24)\end{array}$ & $\begin{array}{c}19.77 \pm 2.20 \\
(16-24)\end{array}$ & $\begin{array}{l}F=0.659 ; \\
p=0.521\end{array}$ \\
\hline 2. & $\begin{array}{c}\text { Mean } \mathrm{BMI} \pm \mathrm{SD} \\
\text { (Range) in } \mathrm{kg} / \mathrm{m}^{2}\end{array}$ & $\begin{array}{c}22.20 \pm 2.82 \\
(17.30-29.80)\end{array}$ & $\begin{array}{c}23.95 \pm 2.59 \\
(18.75-29.60)\end{array}$ & $\begin{array}{l}23.95 \pm 3.56 \\
(19.5-35.67)\end{array}$ & $\begin{array}{l}F=2.359 \\
p=0.103\end{array}$ \\
\hline 3. & $\begin{array}{l}\text { Mean WC } \pm S D \\
\text { (Range) in } \mathrm{cm}\end{array}$ & $\begin{array}{c}75.17 \pm 7.44 \\
(63-84)\end{array}$ & $\begin{array}{c}77.16 \pm 5.91 \\
(65-85)\end{array}$ & $\begin{array}{c}72.55 \pm 6.94 \\
(63-85)\end{array}$ & $\begin{array}{l}F=2.490 \\
p=0.091\end{array}$ \\
\hline 4. & $\begin{array}{l}\text { Mean } \mathrm{HC} \pm \mathrm{SD} \\
\text { (Range) in } \mathrm{cm}\end{array}$ & $\begin{array}{c}92.67 \pm 2.94 \\
(87-100)\end{array}$ & $\begin{array}{c}92.88 \pm 2.80 \\
(87-99)\end{array}$ & $\begin{array}{c}92.50 \pm 2.47 \\
(89-99)\end{array}$ & $\begin{array}{l}F=0.196 \\
p=0.901\end{array}$ \\
\hline 5. & $\begin{array}{c}\text { Mean WHR } \pm \text { SD } \\
\quad \text { (Range) }\end{array}$ & $\begin{array}{c}0.81 \pm 0.07 \\
(0.70-0.90)\end{array}$ & $\begin{array}{c}0.83 \pm 0.05 \\
(0.71 \pm 0.90)\end{array}$ & $\begin{array}{c}0.79 \pm 0.07 \\
(0.68-0.91)\end{array}$ & $\begin{array}{l}F=2.269 \\
p=0.112\end{array}$ \\
\hline
\end{tabular}

$\mathrm{P}<0.05$ was significant value

Table 5: Correlation of the Baseline clinical features of PCOS among the three groups

\begin{tabular}{|c|c|c|c|c|c|c|c|c|c|}
\hline \multirow[t]{2}{*}{ SN } & \multirow[t]{2}{*}{ Characteristics } & \multicolumn{2}{|c|}{$\begin{array}{c}\text { Groupl } \\
(n=21) \\
\text { COCs }\end{array}$} & \multicolumn{2}{|c|}{$\begin{array}{l}\text { Group II ( } n=21) \\
\text { Myo-inositol }\end{array}$} & \multicolumn{2}{|c|}{$\begin{array}{c}\text { Group III ( } n=22) \\
\text { Myo-inositol + } \\
\text { COCs }\end{array}$} & \multicolumn{2}{|c|}{$\begin{array}{c}\text { Statistical } \\
\text { significance }\end{array}$} \\
\hline & & No. & $\%$ & No. & $\%$ & No. & $\%$ & $\chi^{2}$ & 'p' \\
\hline \multirow[t]{6}{*}{1.} & Menstrual abnormalities & & & & & & & & \\
\hline & Normal cycle & 0 & 0 & 1 & 4.8 & 0 & 0 & 4.668 & 0.792 \\
\hline & Oligomenorrhea & 9 & 42.9 & 12 & 57.1 & 11 & 50.0 & & \\
\hline & Secondary Amenorrhea & 6 & 28.6 & 4 & 19.0 & 4 & 18.2 & & \\
\hline & Oligo+hypomenorrhea & 4 & 19.0 & 2 & 9.5 & 3 & 13.6 & & \\
\hline & Oligo+Menorrhagia & 2 & 9.5 & 2 & 9.5 & 4 & 18.2 & & \\
\hline 2. & Acne & 4 & 19.0 & 4 & 19.0 & 5 & 22.7 & 0.121 & 0.941 \\
\hline 3. & Hirsutism (mFG Score) & \multicolumn{2}{|c|}{$(n=8)$} & \multicolumn{2}{|c|}{$(n=5)$} & \multicolumn{2}{|c|}{$(n=6)$} & & \\
\hline & $1-4$ & 0 & 0 & 0 & 0 & 1 & 16.7 & 2.81 & 0.590 \\
\hline & $4-8$ & 3 & 37.5 & 2 & 40.0 & 1 & 16.7 & & \\
\hline & $>8$ & 5 & 62.5 & 3 & 60.0 & 4 & 66.7 & & \\
\hline 4. & Acanthosis nigricans & 3 & 14.3 & 1 & 4.8 & 2 & 9.1 & 1.124 & 0.570 \\
\hline
\end{tabular}


In this present study, Table 6 shows distribution of cases according to improvement in menstrual abnormality after treatment in PCOS among the three groups after 3 months. Improvement in the menstrual abnormality was found in all three groups. Out of all the cases, improvement in Oligomenorrhea was found to be $88.8 \%$ in Group I, 50\% in Group II and $90.9 \%$ in Group III. Improvement in Secondary amenorrhea was $66.7 \%$, 25\% and $75 \%$ in Group I, Group II and Group III respectively.
Improvement in the case of Oligomenorrhea with Hypomenorrhea was found to be $50 \%$ in Group I and II and $66.7 \%$ in Group III, while Oligomenorrhea with Menorrhagia improvement rate was 50\% in Group I and II and $75 \%$ in Group III. Comparatively with combination of Myo-inositol and COCs in Group III, this improvement rate was more $81.4 \%$, followed by Group I -COCs (71.4\%) than Group II- Myo-inositol (45\%).

Table 6: Distribution of cases according to improvement in menstrual abnormality after treatment

\begin{tabular}{|c|c|c|c|c|c|c|c|c|c|}
\hline \multirow[t]{2}{*}{$\begin{array}{c}\text { Menstrual } \\
\text { Abnormality }\end{array}$} & \multicolumn{3}{|c|}{$\begin{array}{c}\text { Group I } \\
\text { (COCs) Drospirenone + Ethinyl } \\
\text { Estradiol }\end{array}$} & \multicolumn{3}{|c|}{$\begin{array}{c}\text { Group II } \\
\text { (Myoinositol) }\end{array}$} & \multicolumn{3}{|c|}{$\begin{array}{c}\text { Group III } \\
\text { (COCs+ Myoinositol) }\end{array}$} \\
\hline & $\begin{array}{c}\text { Before } \\
\text { treatmen } \\
\mathbf{t}\end{array}$ & $\begin{array}{c}\text { After } \\
\text { treatmen } \\
t\end{array}$ & $\begin{array}{l}\text { Improved } \\
\text { (\%) }\end{array}$ & $\begin{array}{c}\text { Before } \\
\text { treatmen } \\
\mathbf{t}\end{array}$ & $\begin{array}{c}\text { After } \\
\text { treatment }\end{array}$ & $\begin{array}{l}\text { Improved } \\
\text { (\%) }\end{array}$ & $\begin{array}{l}\text { Before } \\
\text { treatment }\end{array}$ & $\begin{array}{c}\text { After } \\
\text { treatment }\end{array}$ & $\begin{array}{c}\text { Improved } \\
\text { (\%) }\end{array}$ \\
\hline $\begin{array}{c}\text { Oligomenorrhea } \\
\text { Secondary }\end{array}$ & 9 & 8 & 88.8 & 12 & 6 & 50 & 11 & 10 & 90.9 \\
\hline $\begin{array}{c}\text { Amenorrhea } \\
\text { Oligomenorrhea }\end{array}$ & 6 & 4 & 66.7 & 4 & 1 & 25 & 4 & 3 & 75 \\
\hline $\begin{array}{c}+ \\
+ \\
\text { hypomenorrhea } \\
\text { Oligomenorrhea }\end{array}$ & 4 & 2 & 50.0 & 2 & 1 & 50 & 3 & 2 & 66.7 \\
\hline$\stackrel{+}{+} \underset{\text { Menorrhagia }}{ }$ & 2 & 1 & 50.0 & 2 & 1 & 50 & 4 & 3 & 75 \\
\hline Total & 21 & 15 & 71.4 & 20 & 9 & 45 & 22 & 18 & 81.4 \\
\hline
\end{tabular}

None of the patients had significant changes in the clinical features i.e. hirsutism, Acne, Acanthosis nigricans. Changes in all the other anthropometric parameters (WC, HC \& WHR) were not observed in all the three treatment groups except for BMI, which was significantly reduced $(p=0.035)$ in Group II patients who received Myo-inositol. Levels of Serum Prolactin and FSH did not change in all the three treatment groups after 3 months (Table 6).

In this study, Table 7 shows COCs (Drospirenone 3mg + Ethinyl Estradiol $30 \mu \mathrm{g}$ ) treatment positively affected biochemical and hormonal profile as evident by reduction in Free Testosterone ( $p=0.035), F A I(p=0.043)$, LH levels $(p=0.003)$ with the increase in SHBG $(<0.001)$ without harming weight and BMI.

Myo-inositol supplementation (2 g per day with $200 \mu \mathrm{g}$ folic acid for 3 months) ameliorates body weight and BMI $(p=0.035)$ and significantly reduces Insulin resistance.
This was evident by the reduction in the levels of Fasting insulin ( $p=0.032)$, Fasting Glucose $(p=0.024)$ and HOMAIR (0.024). LH release was effectively suppressed $(p=0.030)$ by these compounds and consequently the androgen production from the ovary; increased sex hormone binding protein (SHBG) synthesis was also observed though it was not statistically significant along with reduction in the levels of circulating free testosterone ( $p=0.027)$.

In the combined Group III, altogether statistically significant change was found in the entire hormonal and biochemical as well as metabolic profile (Table 7). Along with very significant increase in SHBG $(p<0.001)$, there was decline in the Total Testosterone $(p<0.001)$, Free testosterone $(p=0.001)$, FAI $(p=0.041)$ and LH $(p=0.002)$ values, reduction in Fasting Insulin $(p=0.045)$, Fasting Glucose $(p=0.050)$ as well as HOMA-IR $(p=0.041)$. 
Table 7: Comparison of changes in various Anthropometric, hormonal and biochemical parameters before and after treatment in the three study groups

\begin{tabular}{|c|c|c|c|c|c|c|c|c|c|c|c|c|c|c|c|c|}
\hline \multirow{4}{*}{ SN } & \multirow{4}{*}{ Characteristics } & \multicolumn{5}{|c|}{ Group I ( $n=21)$} & \multicolumn{5}{|c|}{ Group II ( $n=21)$} & \multicolumn{5}{|c|}{ Group III (n=22) } \\
\hline & & \multicolumn{5}{|c|}{ COCs } & \multicolumn{5}{|c|}{ Myo-inositol } & \multicolumn{5}{|c|}{ Myo-inositol + COCs } \\
\hline & & \multicolumn{2}{|c|}{$\begin{array}{c}\text { Before } \\
\text { treatment }\end{array}$} & \multicolumn{2}{|c|}{$\begin{array}{c}\text { After } \\
\text { treatment }\end{array}$} & \multirow[t]{2}{*}{ 'p' } & \multicolumn{2}{|c|}{$\begin{array}{c}\text { Before } \\
\text { treatment }\end{array}$} & \multicolumn{2}{|c|}{$\begin{array}{c}\text { After } \\
\text { treatment }\end{array}$} & \multirow[t]{2}{*}{ ' $p$ ' } & \multicolumn{2}{|c|}{$\begin{array}{c}\text { Before } \\
\text { treatment }\end{array}$} & \multicolumn{2}{|c|}{ After treatment } & \multirow[t]{2}{*}{$p^{\prime}$} \\
\hline & & Mean & SD & Mean & SD & & Mean & SD & Mean & SD & & Mean & SD & Mean & SD & \\
\hline 1. & $\mathrm{BMI}\left(\mathrm{kg} / \mathrm{m}^{2}\right)$ & 22.20 & 2.82 & 22.69 & 2.62 & 0.118 & 23.95 & 2.59 & 23.30 & 2.72 & $0.035^{*}$ & 23.95 & 3.56 & 23.74 & 3.44 & 0.167 \\
\hline 2. & $W C(\mathrm{~cm})$ & 75.17 & 7.44 & 75.17 & 7.44 & 1.000 & 77.16 & 5.91 & 77.16 & 5.91 & 1.000 & 72.55 & 6.94 & 72.55 & 6.94 & 1.000 \\
\hline 3. & $\mathrm{HC}(\mathrm{cm})$ & 92.67 & 2.94 & 92.67 & 2.94 & 1.000 & 92.88 & 2.80 & 92.88 & 2.80 & 1.000 & 92.50 & 2.47 & 92.50 & 2.47 & 1.000 \\
\hline 4. & WHR & 0.81 & 0.07 & 0.81 & 0.07 & 1.000 & 0.83 & 0.05 & 0.83 & 0.05 & 1.000 & 0.79 & 0.07 & 0.79 & 0.07 & 1.000 \\
\hline 5. & Prolactin & 12.87 & 7.14 & 12.83 & 6.99 & 0.776 & 14.76 & 8.27 & 14.71 & 8.04 & 0.577 & 14.82 & 8.44 & 14.72 & 8.27 & 0.233 \\
\hline 6. & $\mathrm{TT}$ & 1.09 & 0.56 & 1.07 & 0.46 & 0.786 & 0.91 & 0.61 & 0.91 & 0.48 & 1.000 & 1.05 & 0.46 & 0.94 & 0.42 & $<0.001^{*}$ \\
\hline 7. & $\mathrm{FT}$ & 1.54 & 0.58 & 1.32 & 0.26 & $0.035^{*}$ & 1.38 & 0.43 & 1.19 & 0.17 & $0.027^{*}$ & 1.57 & 0.46 & 1.22 & 0.17 & $0.001^{*}$ \\
\hline 8. & SHBG & 65.34 & 10.93 & 73.43 & 8.69 & $<0.001^{*}$ & 66.38 & 12.17 & 66.90 & 13.72 & 0.508 & 65.23 & 14.26 & 69.95 & 12.25 & $<0.001^{*}$ \\
\hline 9. & FAl & 1.69 & 0.81 & 1.47 & 0.62 & $0.043^{*}$ & 1.38 & 0.95 & 1.38 & 0.75 & 0.929 & 1.88 & 1.87 & 1.44 & 0.99 & $0.041^{*}$ \\
\hline 10. & LH & 7.90 & 2.11 & 7.29 & 1.88 & $0.003^{*}$ & 7.74 & 3.50 & 7.20 & 3.20 & $0.030^{*}$ & 8.18 & 3.02 & 6.90 & 2.34 & $0.002^{*}$ \\
\hline 11 & FSH & 4.90 & 1.57 & 4.87 & 1.47 & 0.855 & 4.81 & 1.40 & 4.81 & 1.36 & 0.968 & 4.58 & 1.63 & 4.58 & 1.62 & $0.776^{*}$ \\
\hline 12. & F. Ins & 12.07 & 4.40 & 12.05 & 3.94 & 0.916 & 12.25 & 4.66 & 11.49 & 4.03 & $0.032^{*}$ & 14.01 & 5.27 & 13.71 & 4.92 & $0.045^{*}$ \\
\hline 13. & F. Glucose & 82.86 & 5.96 & 81.70 & 5.95 & 0.102 & 81.38 & 7.27 & 79.95 & 7.30 & $0.024^{*}$ & 84.85 & 8.10 & 81.32 & 9.37 & $0.050^{*}$ \\
\hline 14. & HOMA-IR & 2.47 & 0.93 & 2.43 & 0.82 & 0.354 & 2.45 & 0.94 & 2.28 & 0.86 & $0.024^{*}$ & 2.93 & 1.14 & 2.73 & 0.95 & $0.041^{*}$ \\
\hline
\end{tabular}

Asterisk $(*)$ is significant valve, $p>0.05$ Not significant, $p<0.05$ Significant, $p<0.01$ Highly significant ${ }_{L} p<0.001$ very highly significant

\section{DISCUSSION}

The observation of our study revealed that mean age of girls under study was $20.16 \pm 2.14$ years. The maximum proportion of women was in the age group of $>19-24$ years $(60.9 \%)$ i.e. young adult, followed by 14 to $\leq 19$ years (39.1\%) i.e. adolescent period. (Table 1 ) This was similar to the previous study on clinical characteristics of polycystic ovary syndrome in Indian women where the mean age of participants was $22.05 \pm 4.64^{[12]}$. Nair et al. ${ }^{[13]}$ in their study also found the maximum number of cases were between 21 to 25 years of age. Age at menarche ranged from 11-15 years in our study.
Maximum were between 12-14 years (71.9\%) with mean age at menarche of $12.23 \pm 0.97$ years. It was $13.71 \pm 1.39$ years in the study conducted by Ramanand et al. ${ }^{[12]}$. A previous study showed adolescent girls aged $12-16$ years and observed that maximum girls attain menarche between $13-15$ years ${ }^{[13]}$. Similar to the present study the mean age of menarche was found to be $12.62 \pm 1.11$ years, in a cross-sectional observational study ${ }^{[14]}$. In healthy adolescents in the first year after menarche half of the cycles were an ovulatory. $70 \%$ of the case has extremely high risk of PCOS, if menstrual irregularity occurs two years after menarche ${ }^{[12]}$. 
In our study, it emphasizes that even nonobese women are also at risk for developing PCOS, $25 \%$ of cases were obese, while $75 \%$ were nonobese. $43.8 \%$ patients under study normal weight (BMI= 18.5-22.9), 28.1\% patients were overweight (BMI =23-24.9), 25\% were obese (BMI $\geq 25$ ), while $5.1 \%$ were underweight (BMI<18.5). Our result was similar to that of the previous study conducted by Kalra et al. ${ }^{[7]}$ in which the percentage of obese, overweight and normal BMI in Indian POCS women $(n=65)$ based on ACOG criteria was $15.38 \%$, $44.61 \%$, and $40 \%$, respectively. According to a crosssectional analysis, PCOS is more prevalent in adolescent and young females, $71.8 \%$ were non-obese, $7.5 \%$ of cases were overweight, and $20.7 \%$ were obese ${ }^{[15]}$. Contrary to that Yildiz et al. ${ }^{[16]}$ in their study on the impact of obesity on incidence of PCOS found that the prevalence rates of PCOS in underweight, normalweight, overweight, and obese women were 8.2, 9.8, 9.9, and $9.0 \%$, respectively and concluded that obesity minimally increases risk of PCOS. A similar result was observed in our study signified that PCOS was neither confined nor prevalent among obese patients, instead, it is very common among normal weight and even in underweight women. WHR (Waist Hip Ratio) $\geq 0.85 \%$ was observed in $54.7 \%$ of cases indicating that central obesity can be seen even at low BMI. According to WHR, PCOS patients had divided into two groups using value of WHR of 0.85 as cutoff: into upper body obesity (WHR $\geq 0.85$ ) and lower body obesity (WHR <0.85) ${ }^{[17]}$. In our study, $31.3 \%$ of cases had waist circumference $>80 \mathrm{~cm}$, while $54.7 \%$ of patients had WHR $\geq 0.85$ and $45.3 \%$ had WHR $<0.85$ in comparison to the previous study, who found that waist circumference was $>88 \mathrm{~cm}$ in $44 \%$ of the patients and WHR $>0.85$ was seen in $38 \%$ of the patients highlighting that Indians have more central obesity even at low BMI ${ }^{[14]}$. A study showed that high WHR was associated with greater disturbance in reproductive hormones in PCOS and is a simple measurement to identify obese patients who are at a greater risk of developing metabolic syndrome. Women with android obesity seem to be more prone to develop menstrual irregularity and infertility ${ }^{[17]}$. After 3 month treatment, there were no changes observed in anthropometric parameters (WC, HC \& WHR) in all three treatment groups except for BMI, which was significantly reduced in Group II patients who received Myo-inositol.
Levels of Serum Prolactin and FSH did not change in all the three treatment groups after 3 months.

In the present study out of the total, clinical symptom of hyperandrogenism in the form of acne was present in $20.3 \%$ and hirsutism was present in $29.7 \%$ of cases. Acanthosis nigricans was found in $9.4 \%$ of cases. This was comparatively lower than the observed in the previous studies ${ }^{[18]}$ quoted that majority of women (80\%) show signs of androgen excess and it plays a major role in the pathophysiology of the condition (PCOS) ${ }^{[10,17]}$. Our result was comparable to prospective interventional study, they found $26.7 \%$ cases had hirsutism, $20 \%$ cases had acne and $9.3 \%$ cases had acanthosis [19] but in our present study none of the patients had significant changes in hirsutism, Acne, Acanthosis nigricans. OCPs effectively reduce hirsutism and acne in women with PCOS after treatment improvement occur ${ }^{[5]}$.

Most of the cases, in our study presented with the abnormal menstrual cycle $98.4 \%$. The menstrual problem in our present study in PCOS ranged from oligomenorrhea to amenorrhea. Oligomenorrhea is a commonest problem; an-ovulation is the pathognomic feature of PCOS and results in irregular menstrual cycles. Therefore, persistent menstrual irregularities (resulting from anovulation) seem to be better predictors compared to biochemical parameters. Oligomenorrhea is one of the diagnostic criteria of PCOS ${ }^{[20,21]}$. This prospective study observed the change in the anthropometric, clinical, biochemical parameters and hormonal levels after treatment with two different drug supplementations, myo-inositol and combined oral contraceptives and the combination of both along with life style modification in each of the three groups.

In our present study, we had this significant observation that combined therapy with both COCs with Myo-inositol in the menstrual abnormality had better improvement rates than COCs and Myo-inositol alone. Though statistically significant improvement in the terms of spontaneous onset of menstrual cycle was observed in all the three study groups but it was more significant in the combined group and least in the Myo-inositol group. Insulin-lowering agents improve ovulation in about half of cases and modestly reduce androgen levels. They are not as effective as COCs in controlling menstrual cyclicity or hirsutism ${ }^{[22]}$. Ozay et al. ${ }^{[23]}$ found in their study on 106 PCOS women that after three months of treatment, patients receiving $\mathrm{COCs}$ showed no menstrual 
irregularity, whereas the decrease of menstrual irregularity in the group receiving Myo-inositol was from $40(76.9 \%)$ to $8(15.4 \%)$. Minozzi et al. ${ }^{[9]}$ in a prospective study comparing the performance of combined contraceptive pill (COCs) in combined effect with Myoinositol on metabolic, endocrine and clinical parameters in 155 pcos patients, researchers discovered that after 12 months, combined treatment with Myo-inositol and COCs had a significant effect on the clinical symptoms (hirsutism) of PCOS. Recent studies demonstrate the effectiveness of Myo-inositol in the treatment of hirsutism and other cutaneous disorders in young women with PCOS ${ }^{[23,24]}$.

In our study, we did not find any significant changes in all the three groups in the anthropometric and clinical manifestations like WC (Waist circumference), WHR (Waist hip ratio), hirsutism, acne and acanthosis nigricans. This may be due to the short duration of our study. Pkhaladze et al. ${ }^{[10]}$ in their study on the effect of Myo-inositol and combined oral contraceptives as monotherapy and combined therapy on teenagers affected with PCOS also observed no changes in the anthropometry and clinical symptoms. In the present study, pivotal effect of Myo-inositol was observed in the form of reduction in weight along with BMI in the group of patients who received Myo-inositol. Gerli et al. ${ }^{[24]}$ in their randomized, double blind placebo-controlled trial to see the effects of Myo-inositol on ovarian function and metabolic factors in women with PCOS also observed a significant weight loss ( $p$ value $<0.01 \%$ ) in the patients treated with Myo-inositol.

In our study, no change was observed in the weight and $\mathrm{BMI}$ in the group of patients, who received combined treatment with Myo-inositol and COCs, this observation was supported by Manozi et al in their study who found no change in the BMI in the combined group (Myoinositol+ COCs) ${ }^{[10]}$. Apparently, this may be due negative effect of COCs being balanced by Myo-inositol ${ }^{[23]}$.

In this study, after treatment with Myo-inositol there was no significant reduction in androgens level except for free testosterone (FT), which was reduced significantly. This result is similar to Lali Phakaldze et al. ${ }^{[10]}$. However after treatment with Myo-inositol significant reduction in $\mathrm{LH}$ level was observed in our study, which is a precondition for antiandrogenic activity, and was also reported by other authors ${ }^{[23]}$. In this group also we did not find any significant change in the levels of FSH.

Pkhaladze et al. ${ }^{[10]}$ also found increase in weight and BMI after receiving Yarina (COCs containing drospirenone) for 3 months in teenagers affected with PCOS. In contrast in our study, there was no change in the weight and BMI in patients who received COCs. This may be attributed to drospirenone containing pills in which, this effect is less expressed $^{[25,26]}$.

A significant change in the metabolic profile was not observed with Drospirenone containing COCs, rather in combination with Myo-inositol improvement was found. The findings of this prospective, open-label research indicated that combining COCs and Myo-inositol is far more successful way for treating the medical symptoms of PCOS (menstrual abnormality) and regulating the endocrine disorders associated with hyperandrogenism than COCs and Myo-inositol alone as single monotherapy in adolescent and young women affected with PCOS. A significant change in the metabolic profile was not observed with Drospirenone containing COCs, rather in combination with Myo-inositol improvement was found.

In our study, all three treatment groups experienced a change in hormonal profile, with the combined study (COCs with Myo-inositol) participants experiencing a slightly higher decrease in serum androgen concentrations (total testosterone, free testosterone). Pkhaladze et al. ${ }^{[10]}$ found slight decreased in adrenal androgen production they found significant reduction after combination with Myo-inositol and OCPs. Moreover, unlike COCs alone, the combination of COCs and Myo-inositol was found to be successful on glucose and insulin profile in our research, previously it confirming that COCs therapy can negatively affect insulin resistance and glucose tolerance. COCs therapy's detrimental effects on hyper-insulinemia and insulin resistance may be counterbalanced by adding an insulinsensitizing drug, such as Myo-inositol. One of the limitations of the present study was its small sample size owing to which potential additional effects of treatment on outcome could not be studied properly. Hence, further studies on larger sample size and with longer duration of intervention are recommended. 


\section{CONCLUSIONS}

Our findings indicated that a regimen of combined oral contraceptives and Myo-inositol may be more efficient than COCs or Myo-inositol alone in regulating biochemical, endocrine, metabolic, and clinical profile in PCOS patients, as well as improving insulin levels and insulin resistance.

Hence, as a result, treating PCOS symptoms with a combination of COCs and Myo-inositol may be a more successful long-term treatment option.

\section{CONTRIBUTION OF AUTHORS}

Research concept: Prof. Sujata Deo

Research design: Prof. Sujata Deo, Dr. Khushbu Pandey

Supervision: Prof. Sujata Deo and Prof. S.P Jaiswar, Dr. Narendra Deo

Data collection: Dr. Khushbu Pandey

Data analysis and interpretation: Prof. Mohd. Kleem, Dr. Pratibha kumari

Writing article: Dr. Pratibha kumari

Final approval: Prof. Sujata Deo

\section{REFERENCES}

[1] Franks S. Polycystic ovary syndrome. N Engl J Med., 1995; 333(13): 853-61.

[2] Malik S, Jain K, Talwar P, Prasad S, Dhorepatil B, et al. Management of Polycystic Ovary Syndrome in India. Fertil Sci., 2014; 1(1): 23-43.

[3] The Rotterdam ESHRE/ASRM-Sponsored PCOS Consensus Workshop Group. Revised 2003 consensus on diagnostic criteria and long-term health risks related to polycystic ovary syndrome (PCOS). Hum Reprod., 2004; 19(1): 41-47.

[4] Thessaloniki ESHRE/ASRM-Sponsored PCOS Consensus Workshop Group. Consensus on infertility treatment related to polycystic ovary syndrome. Fertil Steril., 2008; 89(3): 505-22.

[5] Fauser BCJM, Tarlatzis BC, Rebar RW, Legro RS, Balen $\mathrm{AH}$, Lobo $\mathrm{R}$, et al. Consensus on women's health aspects of polycystic ovary syndrome (PCOS): the Amsterdam ESHRE/ASRM-sponsored 3rd PCOS consensus workshop group. Fertil Steril., 2012; 97(1): 28-38 e25.

[6] Sortino MA, Salomone S, Carruba MO, Drago F. Polycystic ovary syndrome: insights into the therapeutic approach with Inositols. Front Pharmacol., 2017; 8: 341.
[7] Kalra B, Kalra S, Sharma J. The inositols and polycystic ovary syndrome. Indian J Endocrinol Metab., 2016; 20(5): 720-24.

[8] Moran LJ, Brinkworth GD, Norman RJ. Dietary therapy in polycystic ovary syndrome. Semin Reprod Med., 2008; 26(1): 85-92.

[9] Minozzi M, D'Andrea G, Unfer V. Treatment of hirsutism with myo-inositol: a prospective clinical study. Reprod Biomed Online., 2008; 17(4): 579-82.

[10]Pkhaladze L, Barbakadze L, Kvashilava N. MyoInositol in the Treatment of Teenagers Affected by PCOS. Int J Endocrinol., 2016; 2016: 1473612.

[11]Misra A, Chowbey P, Makkar BM, et al. Consensus Statement for Diagnosis of Obesity, Abdominal Obesity and the Metabolic Syndrome for Asian Indians and Recommendations for Physical Activity, Medical and Surgical Management . J Assoc Physicians India, 2009; 57: 163-70.

[12]Ramanand SJ, Ghongane BB, Ramanand JB, Patwardhan $\mathrm{MH}$, Ghanghas $\mathrm{RR}$, et al. Clinical characteristics of polycystic ovary syndrome in Indian women. Indian J Endocrinol Metab., 2013; 17(1): 138-45.

[13]Nair P, Grover V, Kannan A. Awareness and practices of menstruation and pubertal changes amongst unmarried female adolescents in a rural area of East Delhi. Indian J Community Med., 2007:1; 32(2): 15657.

[14]Spandana JC, Prasanna K, Shetty K, Prasanna K, Shetty K. A study on the clinical, biochemical and hormonal profile of polycystic ovary syndrome patients attending tertiary care hospital. Int J Reprod Contraception, Obstet Gynecol 2017; 6(5): 1986-92.

[15]Joshi B, Mukherjee S, Patil A, Purandare A, Chauhan $S$, et al. A cross-sectional study of polycystic ovarian syndrome among adolescent and young girls in Mumbai, India. Indian J Endocrinol Metab [Internet]., 2014; 18(3): 317-24.

[16]Yildiz BO, Knochenhauer ES, Azziz R. Impact of obesity on the risk for polycystic ovary syndrome. J Clin Endocrinol Metab. 2008; 93(1): 162-68.

[17]Hollmann M, Runnebaum B, Gerhard I. Impact of waist-hip-ratio and body-mass-index on hormonal and metabolic parameters in young, obese women. Int J Obes Relat Metab Disord., 1997; 21(6): 476-83.

[18]Choudhary A, Jain S, Chaudhari P. Prevalence and symptomatology of polycystic ovarian syndrome in 
Indian women: is there a rising incidence? Int J Reprod Contraception, Obstet Gynecol., 2017; 6(11): 4971-75.

[19]Roe AH, Dokras A. The Diagnosis of Polycystic Ovary Syndrome in Adolescents. Rev Obstet Gynecol [Internet]., 2011; 4(2): 45-51.

[20]Ahmadi A, Akbarzadeh M, Mohammadi F, Akbari M, Jafari B, et al. Anthropometric characteristics and dietary pattern of women with polycystic ovary syndrome. Indian J Endocrinol Metab [Internet]., 2013; 17(4): 672-76.

[21]Barbieri RL, Ehrmann DA. Metformin for the treatment of polycystic ovary syndrome. Last accessed on $26^{\text {th }}$ September, 2018.

[22]Minozzi M, Costantino D, Guaraldi C, Unfer V. The effect of a combination therapy with myo-inositol and a combined oral contraceptive pill versus a combined oral contraceptive pill alone on metabolic, endocrine, and clinical parameters in polycystic ovary syndrome. Gynecol Endocrinol. 2011; 27(11): 920-24.
[23]Ozay AC, Emekci OO, Okyay RE, Cagliyan E, Kume T, et al. Corrigendum to "Different Effects of Myoinositol plus Folic Acid versus Combined Oral Treatment on Androgen Levels in PCOS Women". Int J of Endocrinol., 2016; 2016: 1-8.

[24]Gerli S, Papaleo E, Ferrari A, Di Renzo GC. Randomized, double blind placebo-controlled trial: effects of myo-inositol on ovarian function and metabolic factors in women with PCOS. Eur Rev Med Pharmacol Sci., 2007; 11(5): 347-54.

[25]Christakou C, Kollias A, Piperi C, Katsikis I, Panidis D, et al. The benefit-to-risk ratio of common treatments in PCOS: effect of oral contraceptives versus metformin on atherogenic markers. Hormones (Athens), 2014; 13(4): 488-97.

[26]Mathur R, Levin O, Azziz R. Use of ethinylestradiol/drospirenone combination in patients with the polycystic ovary syndrome. Ther Clin Risk Manag., 2008; 4(2): 487-92. 